\title{
A DIMENSÃO HUMANA DO SERVIÇO DE AMARRAÇÃO DA ARMADURA DE LAJE DE CONCRETO ARMADO: CONTRIBUIÇÕES DA ERGONOMIA
}

\section{The Human Dimension of the Mooring Service of Armor Reinforced Concrete Slab: Contributions of Ergonomics}

\author{
Douglas De Matos Pereira', Nerio De Mattia Junior ${ }^{2}$, Willians Cassiano Longen ${ }^{3}$ \\ Recebido em 11 de novembro de 2015; recebido para revisão em 12 de fevereiro de 2016; aceito em 18 de maio de \\ 2016; disponível on-line em 15 de junho de 2016.
}

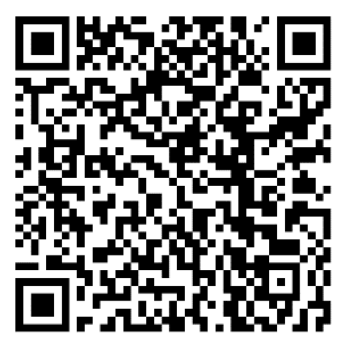

PALAVRAS CHAVE:

Ergonomia;

Construção Civil;

Execução de Estruturas Armadas;

Laje de Concreto Armado; Postura.

KEYWORDS:

Ergonomics;

Civil Construction;

Reinforced Concrete Slab; Posture.

\footnotetext{
* Contato com os autores:
}

1 e-mail: labiomec@unesc.net

2 e-mail: neriodemattia@hotmail.com (N. de Mattia)

Bolsista de Iniciação Científica (PIBIC) do Núcleo de Estudos e Pesquisas em Saúde do Trabalhador - NEPST da UNESC.

3 e-mail: willians@unesc.net (W. C. Longen)

Fisioterapeuta, Pofessor Dr, do Prog. de Pós-Graduação em Saúde Coletiva - PPGSCol/Mestrado Profissional e do NEPST da UNESC. país, apesar dos grandes capitais envolvidos neste setor ele ainda se destaca pelo grande número de acidentes de trabalho, ambientes insalubres e lesões musculoesqueléticas envolvendo seus trabalhadores. Este trabalho tem como objetivo analisar ergonomicamente o serviço de distribuição e amarração da armadura da laje de concreto armado. Realizou-se a organização e a compilação dos dados através de estatística descritiva a partir dos dados de um questionário e observações diretas e instrumentais com registros fotográficos e filmagens aplicados junto aos 15 trabalhadores do setor de armação de lajes de 6 obras localizadas na cidade de Torres/RS. Os dados obtidos na presente pesquisa servem de subsídio para compreender melhor as queixas dos trabalhadores e métodos para poder atenuálas. Foram apresentadas medidas preventivas para aliviar as dores musculoesqueléticas dos colaboradores. Verificou-se que apesar do trabalho realizado pelo armador oferecer riscos biomecânicos mostrou-se que com a colaboração das empresas envolvidas e com medidas de Segurança do Trabalho é possível adotar ações para reduzir estes riscos ao trabalhador. Este trabalho carrega contribuições práticas para a atenuação do risco ergonômico inerente a atividade de amarração de armadura de laje de concreto armado.

ABSTRACT: The construction area is largely featured in the current economy of the country, despite the large capital cities involved in this sector he still stands out for the large number of work accidents, unhealthy environments and musculoskeletal injuries involving its workers. This study aims to analyze ergonomically and mooring distribution service of the armature of the reinforced concrete slab. The Organization and compilation of data through descriptive statistics from the data of a questionnaire and direct observations and instruments with photographic records and footage applied along 15 industry workers of 6 slabs frame works located in the city of Torres/RS. The data obtained in this research serve as subsidy for a better understanding of the workers 'complaints and methods in order to mitigate them. Preventive measures have been proposed to alleviate musculoskeletal pain of employees. It was found that despite the work done by owner offer biomechanical risks showed that with the collaboration of the enterprises involved and with work safety measures it is possible to adopt actions to reduce these risks to the worker. This work carries practical contributions to the mitigation of the risk inherent in the activity of ergonomic securing armour reinforced concrete slab.

\section{(D. M. Pereira)}

ela Universidade do Extremo Sul Catarinense - UNESC.

RESUMO: A área da construção civil está em grande destaque na economia atual do 


\section{INTRODUÇÃO}

A área da construção civil é responsável por boa parte da economia nacional, gerando grande número de empregos e movimentação de recursos. $\mathrm{O}$ trabalho realizado pelos trabalhadores deste ramo, especialmente dos que atuam diretamente na execução do trabalho nas obras, envolve por vezes o emprego de esforços físicos gerados pelas alavancas dos diferentes segmentos corporais. Estas ações são demandadas em ritmo acelerado especialmente nas grandes obras e na maioria das vezes, são executadas em posições corporais biomecanicamente desfavoráveis. Este cenário é composto por outros elementos como o elevado risco de acidente típico que compõe a atividade humana neste setor (PEREIRA et al, 2015).

O profissional responsável pela armação de ferro está presente na construção desde o início da fundação até o término da estrutura. Ele é responsável pela confecção (corte, montagem, transporte e colocação) das armaduras de aço nos locais onde será feita a concretagem das peças que constituem a estrutura (CARTAXO, 1997; CAMPOS et al, 2012).

Apesar do risco de problemas relacionados à Ergonomia, poucos são os estudos sobre os aspectos humanos envolvidos no trabalho de amarração de armadura de laje, prevalecendo sobremaneira os aspectos técnicos e cuidados com a segurança metodológica e técnica do procedimento (NBR 6118 - ABNT, 2014 e BASTOS, 2015).

A grande maioria dos postos de trabalho na construção civil não segue recomendações ergonômicas, sendo que muitos dos estudos realizados não chegam na prática aos canteiros de obras. Com isso muitos trabalhadores desenvolvem dores e lesões musculoesqueléticas ao longo da vida profissional (PEREIRA et al, 2015).

Dentro de todas as atividades executadas em uma obra, a de armador de ferro destaca-se por possuir posições que são ergonomicamente desconfortáveis, destacandose a atividade de armação da laje de concreto. As queixas dos trabalhadores de dores musculoesqueléticas são frequentes, atingindo praticamente todos os trabalhadores em diversos níveis de intensidade (CARTAXO, 1997).

\section{OBJETIVO}

De forma a firmar melhor conhecimento e buscar soluções que visem reduzir o risco ergonômico nesta atividade de trabalho, o presente estudo teve por objetivo identificar as principais dificuldades percebidas pelos trabalhadores que atuam com a montagem de armaduras, estabelecendo relações com as condições ergonômicas posturais envolvidas no serviço de distribuição e amarração da armadura da laje de concreto armado, definindo propostas de medidas que atenuem o risco ergonômico. Tais medidas poderão colaborar para a melhoria da qualidade de vida no trabalho e aumento da produtividade no canteiro de obra.

\section{METODOLOGIA}

A opção metodológica direciona-se para um misto entre a pesquisa quantitativa e qualitativa com ênfase nos estudos de caso, considerando a riqueza prática de informações e de desafios reais que carregam os canteiros de obras.

Para tanto, foram realizadas visitas em 6 canteiros de obras, localizados na cidade de Torres, no estado do Rio Grande do Sul, totalizando um total de 15 (quinze) armadores entrevistados. A média de idade dos trabalhadores ficou em 36 anos. Sendo que 53\% dos entrevistados estão a menos de 5 anos na profissão. O projeto foi aprovado no Comitê de Ética em Pesquisa e os participantes aderiram voluntariamente à pesquisa por meio da assinatura de um Termo de Consentimento Livre e Esclarecido (TCLE).

Foram realizadas observações diretas, apoiadas em registros instrumentais através de registros fotográficos e filmagens.

A coleta de dados foi realizada por meio da aplicação de um questionário (Anexo 1), com 4 principais dimensões: I. Dados ocupacionais do 
trabalhador; II. Dados antropométricos básicos; III. Características da Atividade; IV. Existência de Sintomas e Localização (CORLETT, 1990). O instrumento foi aplicado junto aos armadores das obras que realizam a atividade em estudo, em tempos diferentes nas 6 obras, visando o momento da amarração de armadura de laje de concreto.

Dentro do bloco III, especificamente no item B utilizou-se a classificação de esforço percebido pelo trabalhador de BORG. A Intensidade da Dor foi avaliada com a Escala Visual Analógica que varia de zero (0) a dez (10), sendo que zero (0) representa a ausência de dor e dez (10) a pior dor percebida.

Os dados foram agrupados e tratados através de estatística descritiva simples. Com base nos resultados obtidos, foi elaborada uma série de orientações com a finalidade de melhorar ergonomicamente as atividades realizadas $\mathrm{e}$ assim minimizar as queixas musculoesqueléticas dos trabalhadores que estão realizando as atividades.

\section{RESULTADOS}

Após o levantamento dos dados constatou-se que todos os entrevistados apresentavam dores musculoesqueléticas após realizar as atividades de trabalho. A região mais citada foi a parte inferior das costas, sendo que $100 \%$ dos entrevistados relataram sentir desconfortos relacionando-os com a grande amplitude de flexão da coluna exigida durante a realização da atividade (Figura 1 ).

No questionário realizado, $87 \%$ responderam que realizam a atividade de montagem de armadura por mais de 4 horas diariamente. A intensidade de esforço percebido pelos trabalhadores prevaleceu com nível moderado (Figura 2).

Os segmentos corporais que os armadores apontaram como envolvidos com os maiores esforços foram o tronco e os membros inferiores (Figura 3).

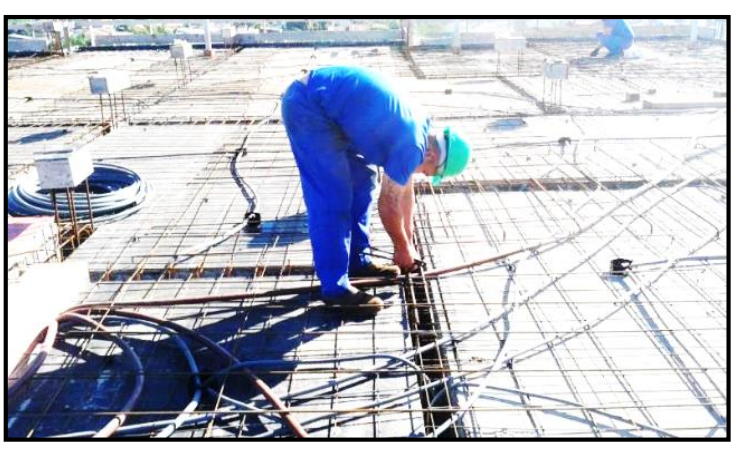

[A] Postura Típica Adotada para a Atividade.

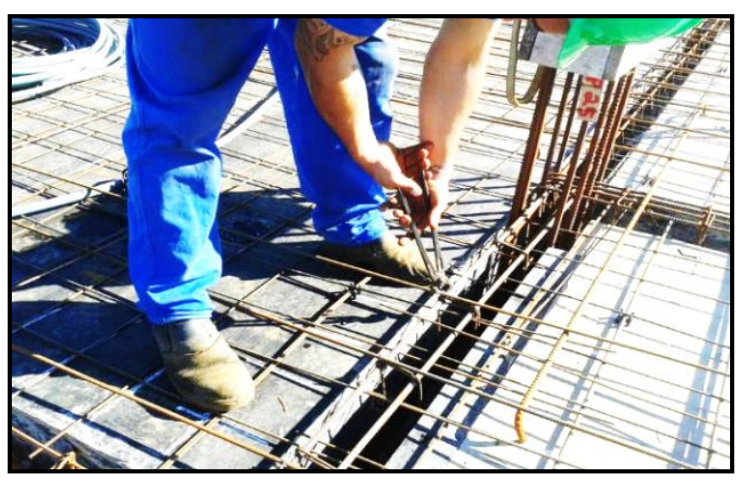

[B] Detalhe da Pega da Torquesa.

FIGURA 1: Registro de posturas de profissionais durante a execução da amarração das armaduras de laje de concreto armado [A] Postura em Hiperflexão do tronco durante a amarração da armadura da laje. [B] Detalhe da torquesa de pequena dimensão utilizada no trabalho manual de amarração.

FONTE: Autoria própria.

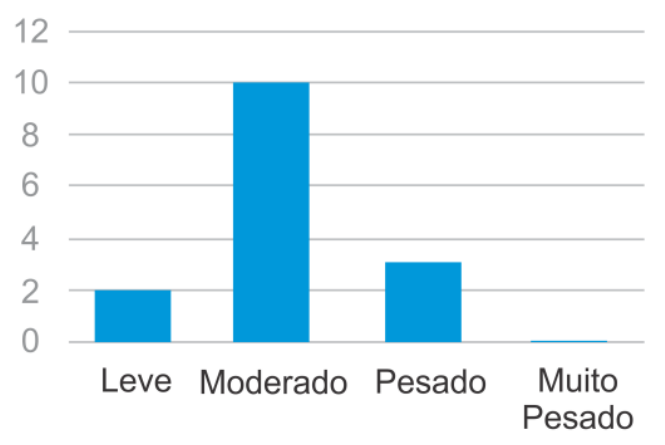

FIGURA 2: Distribuição quantitativa numeral da Intensidade de Esforço Percebida pelos Trabalhadores $(n=15)$. FONTE: Autoria própria.

O tronco é a região mais exigida na realização da atividade na opinião dos armadores. Em segundo lugar ficou os membros inferiores. Já os membros superiores foram pouco referenciados neste aspecto. 
No questionário aplicado com o mapa corporal que explorou as regiões em que os trabalhadores sentiam dores musculoesqueléticas após a realização da atividade de trabalho, bem como, a intensidade desta dor, pode-se observar que as regiões da coluna lombar e sacral são as mais apontadas pelos armadores. Pelo menos uma dessas duas regiões foi apontada por todos os entrevistados, sendo que o mesmo trabalhador podia relatar os sintomas em mais de um segmento corporal.

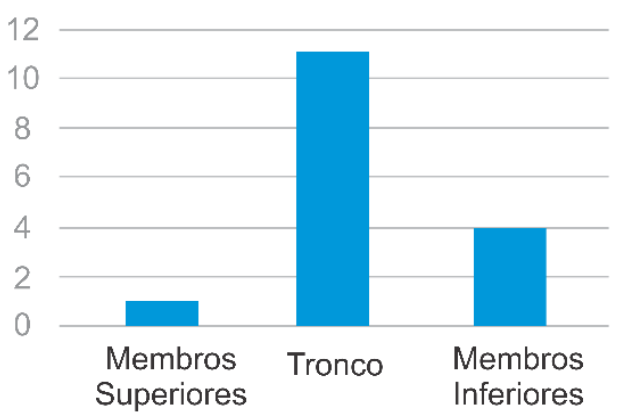

FIGURA 3: Distribuição da Percepção Individual dos Segmentos Corporais Envolvidos com Maior Esforço no Trabalho de Amarração de Armação de Laje de Concreto Armado ( $n=15)$.

FONTE: Autoria própria .

Outra região que chama bastante a atenção é a dos membros inferiores envolvendo coxas, joelhos e pernas, regiões do corpo apontadas como fontes de dor por parte dos armadores (Tabela 1).

TABELA 1: Percepção de Presença de dor por distribuição de segmento corporal.

\begin{tabular}{ll} 
Pescoço & 1 \\
\hline Cervical & 2 \\
\hline Ombros & 1 \\
\hline Costas (Dorsal) & 1 \\
\hline Costas (Lombar) & 8 \\
\hline Região Sacral & 9 \\
\hline Cotovelo & 2 \\
\hline Punho & 3 \\
\hline Coxa & 4 \\
\hline Joelho & 4 \\
\hline Perna & 5 \\
\hline
\end{tabular}

FONTE: Autoria própria.

\section{DISCUSSÃO}

De modo geral, a construção civil tem resistido às inovações tecnológicas e organizacionais que, nos últimos séculos, marcaram a face de quase todos os setores produtivos. Grande parte do processo de trabalho na construção civil continua inteiramente dependente do trabalho manual, ou seja, do trabalho vivo e de suas habilidades, sem poder usar máquinas e organizar a produção em moldes industriais. $O$ processo de produção continua sendo semi-artesanal ou de base artesanal, como na manufatura do início da Revolução Industrial (FONSECA e LIMA, 2007).

Nesta área como os métodos de trabalho são bastante variáveis, portanto sem repetição permanente das suas operações, as tentativas de "racionalização" acabam se frustrando e a alta rotatividade da mão-de-obra no setor dificulta o treinamento de novos métodos de trabalho. Além disto os produtos na construção civil são pouco padronizados e produzidos em pequena escala, quando não únicos, o que impede a adoção de técnicas desenvolvidas a exemplo da produção industrial em larga escala baseadas na padronização, na repetibilidade e na modularização (FONSECA e LIMA, 2007). Esta diversificação por outro lado carrega vantagens ao minimizar o efeito cumulativo típico das linhas de produção.

As atividades exercidas pelos trabalhadores da construção civil, especialmente dos que atuam diretamente no manejo dos materiais e dispositivos, envolvem por vezes o emprego de esforços físicos gerados pelas alavancas corporais dos diferentes segmentos corporais. Estas ações são demandadas em ritmo acelerado especialmente nas grandes obras e executadas em posições corporais por vezes desfavoráveis (PEREIRA et al, 2015).

Um grande esforço no tronco é imposto aos trabalhadores durante a tarefa. Em relação à carga aproximada nos discos intervertebrais inferiores em diferentes posturas, a atividade com a coluna flexionada e joelhos estendidos produz grande sobrecarga no disco (MARCELO, MARTINS 
e LONGEN, 2015). Dentro das posturas inadequadas aquelas que $\mathrm{o}$ trabalhador desenvolve com o tronco hiperfletido, inclinado ou rodado, com o passar do tempo provocam tensões musculares locais, dores na região lombar e desgaste de discos intervertebrais (IIDA, 2003).

Os achados desta pesquisa corroboram com estes aspectos ao se encontrar maior esforço percebido na atividade como sendo para o tronco (coluna dorso-lombo-sacra) e o segmento corporal com maiores queixas para a realização da atividade também envolveu a coluna lombar e a região sacral.

Estes segmentos em conjunto formam a coluna lombosacra, que configura a parte mais baixa da coluna vertebral, que em diferentes estudos mostra-se associada à sobrecarga quanto da hiperflexão do tronco, especialmente quando se utiliza os membros superiores e utensílios manuais (LONGEN, 2013 e PEREIRA et al, 2015).

O trabalho muscular estático, ou seja, aquele que sustenta uma posição corporal, a exemplo do que ocorre na hiperflexão do tronco, experimentado durante a amarria de armação de laje de concreto armado, mostra-se de maior risco do que o trabalho muscular dinâmico. Isso ocorre porquê no trabalho dinâmico há possibilidade de troca circulatória nos tecidos utilizados incluindo músculos, fáscia, nervos e ligamentos, o que é bastante reduzido durante a contração mantida estática (LONGEN, 2013).

Entre as vértebras existem os discos intervertebrais, estruturas fibrocartilaginosas, que são compostas de massa gelatinosa, com mais de $80 \%$ de água e um amortecedor de tensões que se localiza no centro, denominado de núcleo pulposo, que é rodeado por uma camada de fibrocartilagem, denominado anel fibroso, que tem a função de impedir o seu deslocamento excessivo em qualquer direção (PEREIRA et al, 2015).

A atividade de montagem de armadura de laje, especificamente durante a amarração tem predomínio de trabalho estático para o tronco, que quando comparada ao trabalho dinâmico tem um consumo maior de energia, frequência cardíacas maiores e períodos de restabelecimento mais longos. Isto acontece porque no trabalho muscular estático a irrigação sanguínea é tão mais diminuída quanto maior for a produção de força (GRANDJEAN, 1998).

De acordo com Fonseca e Lima (2007) abordando atividade de trabalho similar na construção civil, pode-se destacar particularidades típicas do trabalho neste segmento, sua diversidade e especificidades. Caracterizado como um setor que tem resistido às inovações tecnológicas e organizacionais. Grande parte do processo de trabalho na construção civil continua inteiramente dependente do trabalho manual, ou seja, do trabalho vivo e de suas habilidades, com uso restrito de máquinas e de formas organizacionais, ficando distante neste sentido da produção em moldes industriais. O processo de produção continua sendo semi artesanal ou de base artesanal, como na manufatura do início da Revolução Industrial. A exemplo do trabalho de amarração de armadura de laje. É uma forma bastante manual e dependente do esforço físico dos trabalhadores.

Sobre este esforço envolvido, em relação à força máxima de um músculo a mesma depende da idade, do sexo, da constituição física, do grau de condicionamento físico e da motivação do momento. Referente a idade o ponto máximo da força muscular para homens e mulheres fica entre os 25 e 35 anos de idade (GRANDJEAN, 1998).

Para intervenção da Ergonomia na construção civil existem quatro principais possibilidades de intervenção: (1) Mudanças nos materiais de trabalho; (2) Mudanças nas ferramentas e equipamentos; (3) Mudanças nos métodos e organização do trabalho; (4) Treinamento e programa de exercício (SCHENEIDER, 1995).

Durante a execução do serviço deverão ser realizadas pausas para serem realizados novos alongamentos e fortalecimentos, principalmente na região da coluna. Outra medida proposta para amenizar as dores dos armadores é a modificação da ferramenta utilizada durante a amarração da laje. Normalmente é utilizada uma torquês com um cabo de aproximadamente 27 centímetros. 
Com o cabo da ferramenta alongado o trabalhador segura a torquês mais longe da laje, com isso diminui a inclinação necessária da coluna para realizar a tarefa. Com isto, sugere-se como medidas que visam atenuar a sobrecarga postural e o esforço exigido, o prolongamento do cabo da torquês utilizada para este serviço deve ser considerado, com a finalidade de diminuir a hiperflexão da coluna imposta pelo momento da amarração da laje. Isto não elimina a flexão do tronco, apenas reduz em pequeno grau sua amplitude.

A exploração de pequenos bancos de fácil deslocamento, os programas de exercícios bem direcionados e acompanhados por profissional especializado, bem como, o revezamento entre funções são algumas medidas que podem contribuir para a redução do risco.

No presente estudo, recomenda-se a prática do alongamento antes do início da atividade de amarração da armadura de laje de concreto armado e após o período da atividade realizada. Sempre que possível um programa organizado de Ginástica Laboral conduzido por profissional habilitado configura um cenário mais favorável.

A condição funcional da coluna lombar é determinada pela condição estrutural (anatômica), pelo funcionamento sistêmico (fisiológico) e mecânico integrado (biomecânico) dos segmentos corporais. O equilíbrio lombo pélvico envolvendo os músculos multifídeo, iliocostal lombar, transverso do abdômen, quadrado lombar e diafragma, chamado de estabilização central, determinam a condição biomecânica deste segmento vertebral (MARCELO, MARTINS e LONGEN, 2015).

Sobre estes aspectos físico funcionais é importante considerar que indivíduos com lombalgia tendem a apresentar fraqueza muscular envolvendo principalmente os músculos multífidos e transversos do abdômen, associadas a uma estabilidade inadequada da região central que gera dor. Assim, os programas de exercícios que envolvem a estabilização central ajudam a diminuir quadro álgico e consequentemente, interferir naquele ciclo vicioso que geralmente tem tendência a se instalar, ou seja, fraqueza que leva a instabilidade, que tende a gerar dor, que leva a fraqueza (MARCELO, MARTINS e LONGEN, 2015).

\section{CONCLUSÃO}

A Ergonomia tem como objetivo conhecer os riscos para o trabalhador no ambiente de trabalho e por meio de conhecimento das origens, causas e efeitos permitir desenvolver mecanismos capazes de eliminar, controlar ou diminuir estes riscos. O canteiro de obras mostra-se um grande desafio por estar em constante modificação. Dentre os diversos serviços realizados no canteiro de obras a amarração da armadura de laje de concreto armado destaca-se como um desafio ergonômico pela postura exigida para a realização do serviço. A busca de implementação prática de medidas ergonômicas que passam pela posição do trabalhador, pelas ferramentas utilizadas, associadas à direcionamentos organizacionais representa aspecto bastante relevante. Este estudo permite evidenciar importante problemática envolvendo o trabalho do cotidiano dos canteiros de obra e apresenta medidas que implantadas num contexto global e sistêmico podem reduzir o risco ergonômico, embora não explorem solução plena deste risco biomecânico. Esta atividade, portanto, merece permanecer como foco de atenção por profissionais da Engenharia Civil e da Saúde e Segurança do Trabalho. Este trabalho carrega contribuições práticas para a atenuação do risco ergonômico inerente a atividade de amarração de armadura de laje de concreto armado.

\section{REFERÊNCIAS BIBLIOGRÁFICAS}

ASSOCIAÇÃO BRASILEIRA DE NORMAS TÉCNICAS. Projeto de estruturas de concreto - Procedimento, NBR 6118. Rio de Janeiro, ABNT, 2014, 238p.

BASTOS, Paulo Sérgio dos Santos. Ancoragem e Emenda de Armaduras. Universidade Estadual Paulista. Bauru/SP. 2015 
CAMPOS, Carlos de Oliveira; ROCHA, Adilson Pereira; GOMES, Ronaldo Barros; MELO, Guilherme Sales. Reforço em Lajes de Concreto Armado. Revista Eletrônica de Engenharia Civil - REEC. v.4, n.2, 2012. p. 69-81. Disponível na Internet em: $<$ http://revistas.ufg.br/index.php/reec/article/view/19 838/11798>. Acessado em: 28 de outubro de 2015.

CARTAXO, Cristina; NÓBREGA, Carmen et al. Educação e Treinamento: Medidas Ergonômicas no Posto de Trabalho do Armador de Laje, 8 Congresso Brasileiro de Ergonomia, Florianópolis, p. 348-354, Out. 1997.

CORLETT, E. N. Static Muscle Loading and the Evaluation of Posture. In:CORLETT et al. Evaluation of human work. New York: Taylor \& Francis, 1990. cap.22, p.543-569.

FONSECA, Eduardo D; LIMA, Francisco de P. A. Novas Tecnologias Construtivas e Acidentes na Construção Civil: $O$ Caso da Introdução de um Novo Sistema de Escoramento de Formas de Laje. Revista Brasileira de Saúde Ocupacional. v. 32, n. 115, São Paulo, Jan/June, 2007.

GRANDJEAN, Etienne. Manual de Ergonomia: adaptando o trabalho ao homem. Porto Alegre: Bookman, 1998. 337p. IIDA, Itiro. Ergonomia: Projeto e Produção. São Paulo: Edgard Blücher. 2003. 451 p.

LONGEN, Willians Cassiano. Efeitos do exercício aeróbico e da terapia manual sobre marcadores bioquímicos de lesão musculoesquelética e parâmetros funcionais em motoristas profissionais com lombalgia crônica inespecífica. 2013. 106 p. Tese (Doutorado) - Universidade do Extremo Sul Catarinense, Programa de Pós-graduação em Ciências da Saúde, Criciúma, 2013.

MARCELO, Ana Laura M; MARTINS, Maicon S; LONGEN, Willians C. Avaliação da Funcionalidade e da Força Dinamométrica Lombar de Mineiros do Carvão. Revista Inova Saúde. http://dx.doi.org/10.18616/is.v4i2.2224.115-127, v.4, n.2, Nov. 2015. p. 115-127..

PEREIRA, Cinara Caetano; DEBIASI, Débora Figueró; FARIAS, Joni Márcio; MADEIRA, Kristian; LONGEN, Willians Cassiano. Análise do risco ergonômico lombar de trabalhadores da construção civil através do método NIOSH. DOI: http://dx.doi.org/10.14488/16761901.v15i3.1888. Produção Online. v. 15, p. 914, 2015.

SCHNEIDER, Scott. Implement Ergonomic Interventions in Construction. Applied Occupational and Environmental. p.822-823. Outubro, 1995. 